\title{
Evaluation of Bilateral Mental Nerve Block as an Alternative to General Anesthesia for Resection of Lower Lip Tumors
}

\author{
Ashraf Khater ${ }^{1}$, Islam A. Elzahaby ${ }^{1}$, Mohamed Hamdy ${ }^{1}$, Mohammad Zuhdy ${ }^{1}$, Omar Hamdy ${ }^{1}$, \\ Mohamed Ezzat', Mahmoud Abdelaziz'1, Ahmad M. Farid', Mansour Elmoatasem¹, \\ Amr Hassan', Khalid Atallah', Mahmoud Mostafa Saleh"1, Maha A. Abo-Zeid², Amr Yassin'2, \\ Ola Taha Abd Eldayem², Mona Gad²
}

${ }^{1}$ Department of Surgical Oncology, Mansoura Oncology Center (OCMU), Faculty of Medicine, Mansoura University, Mansoura, Egypt ${ }^{2}$ Anesthesia and Surgical Intensive Care Department, Mansoura University Hospital, Faculty of Medicine, Mansoura University, Mansoura, Egypt

Email: *dr.ashrafkhater@yahoo.com

How to cite this paper: Khater, A., Elzahaby, I.A., Hamdy, M., Zuhdy, M., Hamdy, O., Ezzat, M., Abdelaziz, M., Farid, A.M., Elmoatasem, M., Hassan, A., Atallah, K., Saleh, M.M., Abo-Zeid, M.A., Yassin, A., Abd Eldayem O.T. and Gad, M. (2017) Evaluation of Bilateral Mental Nerve Block as an Alternative to General Anesthesia for Resection of Lower Lip Tumors. Surgical Science, 8, 319-325.

https://doi.org/10.4236/ss.2017.88035

Received: July 13, 2017

Accepted: August 12, 2017

Published: August 15, 2017

Copyright $\odot 2017$ by authors and Scientific Research Publishing Inc. This work is licensed under the Creative Commons Attribution International License (CC BY 4.0).

http://creativecommons.org/licenses/by/4.0/ (c) (i) Open Access

\begin{abstract}
Objective: Nerve blockade is commonly used in oncosurgical procedures as an alternative to general anesthesia for older patients and those with significant medical problems. We report a single tertiary oncology center experience in performing various lip resections and reconstructive techniques using this technique. Patients and methods: sixty patients with lower lip tumors were enrolled into this study with exclusion of refusing, non-compliant and critically ill patients. A solution of $4 \mathrm{ml} 2 \%$ Lidocaine and epinephrine was put in a $5 \mathrm{ml}$ syringe. Half the solution $(2 \mathrm{ml})$ was injected into each side with a 23 gauge needle and after 5 minutes the surgical resection was carried out after testing for anesthesia. Results: The mean age was $68 \pm 6.2$ years. The mean ASA score was $3 \pm 0.75$. There were 4 cases who expressed painful sensation and their operations were completed with fentanyl increments. Mean hospital stay was $1 \pm 0.75$ days. There were three cases of wound gaping who were treated with secondary closure in an outpatient basis. One patient expressed postoperative acute ischemic heart pain that was managed with anti-ischemic measurements. Conclusion: Bilateral mental nerve block is a safe and effective alternative to general anesthesia in lower lip tumors' resection especially in older patients and those with poor tolerance for general anesthesia provided that there is no need for cervical nodal dissection.
\end{abstract}

\section{Keywords}

Mental Nerve Block, Lip Tumors, Lidocaine 


\section{Introduction}

Nerve blockade is not only an anesthetic tool, but it is widely used for treatment of various types of neuralgic and cancer pains [1] [2]. It was introduced as an anesthetic method for a variety of surgical procedures a long time ago [3]. In the field of onco-surgery, various types of resection procedures were done with nerve block techniques; namely the thoracic paravertebral blockade for breast cancer surgeries [4] [5] and the epidural anesthesia that is used widely in many colorectal and genitourinary surgeries with proven opioid sparing effect and better immune functions that may positively improve the cancer survival [6]. Nerve blockade is usually an alternative for general anesthesia, especially for older, morbid patients and those with poor cardiac risk "American Society of Anesthesiologists (ASA)" score [7]. The mental nerve block is one of the nerve blockades that is used to perform a safe lip surgery in case of poor anesthetic tolerance [8]. The mental nerve is a terminal branch of the mandibular nerve of trigeminal. When it leaves the mental foramen which is located midway between the first and second premolars and the inferior alveolar margin, it supplies the lower lip, chin and the related inner gum [8]. This study aimed to assess the effectiveness of bilateral mental nerve block as an adequate sole anesthesia to perform various lip resections and reconstruction among cases admitted to a tertiary oncology center.

\section{Methods}

Sixty patients with lower lip tumors who were admitted for complete resection in a tertiary oncology center were enrolled into this study in the period from February 2016 to June 2017. Table 1 shows their demographic and clinical data. After approval of the local ethical committee and an explanation of the technique and all its sequels to the patients, all preoperative assessments were made, including detailed patients' history with a special focus on the medical history and associated comorbidities, full laboratory assessment and full radiologic evaluation for the tumor and its possible spread. Patients with severe cardiopulmonary disorder, severe organ failure, uncontrolled hypertension, recent stoke or infarction, those who refused or were not compliant with local anesthesia, those with advanced local disease and those with nodal metastases that mandates nodal dissection were excluded from this study. All patients were fasting at least six hours before the procedure with prompt control of blood pressure and blood sugar. The block was carried out under conscious sedation using intravenous midazolam in a dose of $0.03 \mathrm{mg} / \mathrm{kg}$. For the mental nerve block we used the intraoral direct injection after digital palpation of the mental foramen just below the lower first and second premolar teeth midway between the teeth and the alveolar margin (Figure 1). In older patients we intentionally made the injection nearer to the alveolar margin as the foramen gets lower down with the aging process. We used a needle of 23 gauge with a $5 \mathrm{ml}$ syringe. A solution of 4 $\mathrm{ml}$ 2\% Lidocaine with epinephrine 1:100.000 was prepared. After eversion of the 
lower lip, half the amount $(2 \mathrm{ml})$ was injected into each side within 25 seconds with care not to enter the foramina to avoid direct nerve injury together with aspiration before injection to be sure that there is no intravascular injection (Figure 1). After waiting for 5 minutes, a test for sensory block was done using cold perception followed by toothed forceps grasping. Then, tumor resection and lip reconstruction was carried out in the usual fashion with care to avoid blood aspiration (Figure 2, Figure 3). A successful anesthesia was considered

Table 1. Demographic and clinical data of the studied cases $(n=60)$.

\begin{tabular}{ccc}
\hline & Mean \pm SD & Range \\
\hline Age (years) & $68 \pm 6.2$ & $60-78$ \\
BMI $\left(\mathrm{Kg} / \mathrm{m}^{2}\right)$ & $27 \pm 3.4$ & $26-31$ \\
ASA score & $3 \pm 0.75$ & $3-4$ \\
\hline Gender & Number & Percentage \\
Male & & \\
female & 42 & $70 \%$ \\
Comorbidities & 18 & $30 \%$ \\
Hypertension & & \\
DM & 42 & $70 \%$ \\
IHD & 22 & $36.7 \%$ \\
AF & 15 & $25 \%$ \\
COPD & 3 & $5 \%$ \\
Cerebral strokes & 12 & $20 \%$ \\
Controlled hepatic disease & 6 & $10 \%$ \\
Cardiomyopathy & 7 & $11.7 \%$ \\
\hline
\end{tabular}

BMI: Body mass index. ASA: American Society of Anesthesiologists. DM: Diabetes Mellitus. IHD: Ischemic heart disease. AF: atrial fibrillation. COPD: chronic obstructive pulmonary disease.

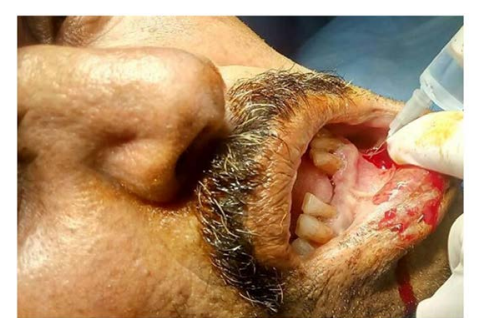

Figure 1. Injection into the nerve exit from the mental foramen.

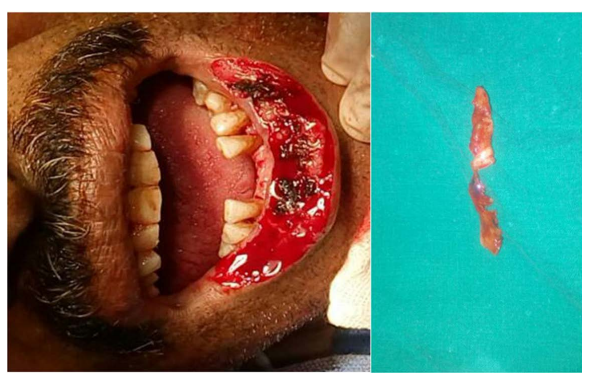

Figure 2. Resected part of the lower lip. 


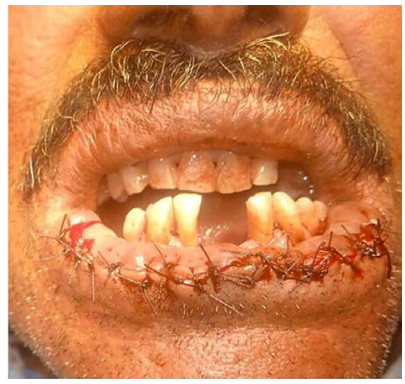

Figure 3. Closure of the defect with lip mucosal advancement technique.

Table 2. Operative and postoperative outcome $(n=60)$.

\begin{tabular}{ccc}
\hline & Number & Percentage \\
\hline Failure & 4 & $6.7 \%$ \\
Mean operative time (min) & $42 \pm 3.4$ & (range: $35-47)$ \\
Operative bleeding & 2 & $3.3 \%$ \\
Wound gaping & 3 & $5 \%$ \\
Infiltrated margins & 4 & $6.7 \%$ \\
Cosmetic disfigurement ${ }^{*}$ & 2 & $3.3 \%$ \\
Cardiac or chest problems & $1^{* *}$ & $1.7 \%$ \\
Mean hospital stay & $1 \pm 0.75$ & $($ range: $1-2)$ \\
\hline
\end{tabular}

*assessed by subjective and objective method; ${ }^{* *}$ one case of acute ischemic chest pain.

when surgery was completed without further need for any anesthetic, analgesic or sedative. When any patient complained of pain related to the surgical procedure, it was considered as an anesthetic failure and intravenous fentanyl 0.5 $\mu \mathrm{g} / \mathrm{kg}$ increment was given. The post-operative consequences were recorded as regard complications and the aesthetic outcome (by both subjective and objective methods through assessment of the lip alignment and sphincteric function).

\section{Results}

Demographic and clinical data are shown in Table 1. Mean age was $68 \pm 6.2$ years. 42 patients were males (70\%) and 12 were females (30\%). There was no difference as regard the technical aspects among males and females. The associated comorbidities were shown reflecting that a considerable number are poor risk patients for general anesthesia. Table 2 shows the operative and postoperative outcome; there was a $6.7 \%$ failure incidence, as four patients complained of intraoperative pain that was managed with IV fentanyl $0.5 \mu \mathrm{g} / \mathrm{kg}$ increment. Two cases showed a postoperative reactionary hemorrhage that was managed conservatively with medications and packing. Three cases showed a postoperative wound gaping that was managed with secondary suturing in an outpatient basis with local anesthesia. One patient expressed postoperative acute ischemic heart pain that was managed with anti-ischemic measures. Mean hospital stay was $1 \pm 0.75$ days. The pathologic varieties of lip tumors are shown in Table 3 . 
Table 3. Pathological varieties $(n=60)$.

\begin{tabular}{ccc}
\hline & Number & Percentage \\
\hline Squamous cell carcinoma & 46 & $76.7 \%$ \\
Basal cell carcinoma & 4 & $6.7 \%$ \\
Keratoacanthoma & 5 & $8.3 \%$ \\
Pseudopapillomatous hypertrophy & 3 & $5 \%$ \\
Leukoplakia & 2 & $3.3 \%$ \\
\hline Details of Squamous cell carcinomas & Mean \pm SD & Range \\
\hline T & $2 \pm 0.75$ & $1-2$ \\
M & 0 & 0 \\
G & 0 & 0 \\
\hline
\end{tabular}

\section{Discussion}

The use of nerve block technique is not new. It is the oldest and simplest way in anaesthetizing patients while keeping them completely conscious and aware. However, many patients are not so compliant with this method and occasionally there is some sort of "escape" that makes the procedure not completely pain free. Moreover, sometimes the extent and magnitude of the operation exceeds the limits of local nerve block and hence the general anesthesia will be a must. Conversely, there are some situations in which, local anesthesia is mandatory especially in older patients and those with poor anesthetic tolerance. This current study shows sixty cases of different lip tumors. All were completely and solely anesthetized with bilateral mental nerve block. The results show nearly $93.3 \%$ success of the technique without any need for general anesthesia. The intraoral rout was preferred over the percutaneous one since it allows palpation of the foramen as a depression with more efficient inner lip anesthesia; this was supported by other studies although results were not statistically significant [9]. In most of our elder patients, we followed the anatomical rules of shifting the mental foramen to a caudal position with the aging process, and this was aided by palpation [10]. The injection was done within a 25 seconds; however, it was shown that the speed of injection does not directly influence the anesthetic outcome [11]. We used epinephrine 1/100,000 among the anesthetic solution to prolong the duration of anesthesia through its vasoconstrictive effect which decreases the lidocaine absorption. Some researchers investigated the effect of massage after injection and found it of no value [12]. The potential hazards of the technique may be listed as; failure which is rare, local postoperative pain that is related to the injection site which was not encountered in any case, postoperative lip sensory defects that are avoided by careful injection without entering the foramen. As regards the oncologic and the aesthetic outcomes, this study showed that this technique was not interfering with the sound surgical procedure and is not responsible for the oncologic failure (infiltrated margins) or the 
cosmetic dissatisfaction.

\section{Conclusion}

Bilateral mental nerve block with lidocaine is a safe and effective alternative to general anesthesia in lower lip tumors' resection and reconstruction, especially in older and morbid patients provided that there is no need for cervical nodal dissection.

\section{Conflict of Interest}

There is no conflict of interest.

\section{References}

[1] Park, H.G., Park, P.G., Kim, W.J., Park, Y.H., Kang, H., Baek, C.W., et al. (2014) Ultrasound-Assisted Mental Nerve Block and Pulsed Radiofrequency Treatment for Intractable Postherpetic Neuralgia: Three Case Studies. The Korean Journal of Pain, 27, 81-85. https://doi.org/10.3344/kjp.2014.27.1.81

[2] Klepstad, P., Kurita, G.P., Mercadante, S. and Sjøgren, P. (2014) Evidence of Peripheral Nerve Blocks for Cancer-Related Pain: A Systematic Review. Minerva Anestesiologica, 81, 789-793.

[3] Tetzlaff, J.E. (2010) Cousins and Bridenbaugh's Neural Blockade in Clinical Anesthesia and Pain Medicine. Mayo Clinic Proceedings, 85, e51. https://doi.org/10.4065/mcp.2010.0230

[4] Moller, J.F., Nikolajsen, L., Rodt, S.A., Ronning, H. and Carlsson, P.S. (2007) Thoracic Paravertebral Block for Breast Cancer Surgery: A Randomized Double-Blind Study. Anesthesia \& Analgesia, 105, 1848-1851. https://doi.org/10.1213/01.ane.0000286135.21333.fd

[5] Simpson, J., Ariyarathenam, A., Dunn, J. and Ford, P. (2014) Breast Surgery Using Thoracic Paravertebral Blockade and Sedation Alone. Anesthesiology Research and Practice, 2014, Article ID: 127467. https://doi.org/10.1155/2014/127467

[6] Brozović, G., Štefančić, L., Goranović, T. and Vrdoljak, D.V. (2015) Regional Anaesthesia in Cancer Surgery: An Update. Periodicum Biologorum, 117, 219-223.

[7] Khater, A., Mazy, A., Gad, M., Taha Abd Eldayem, O. and Hegazy, M. (2017) Tumescent Mastectomy: The Current Indications and Operative Tips and Tricks. Breast Cancer: Targets and Therap, 9, 237-243.

[8] Tan, F.F.S.L., Schiere, S., Reidinga, A.C., Wit, F. and Veldman, P.H. (2015) Blockade of the Mental Nerve for Lower Lip Surgery as a Safe Alternative to General Anesthesia in Two Very Old Patients. Local and Regional Anesthesia, 8, 11-14. https://doi.org/10.2147/LRA.S63246

[9] Syverud, S.A., Jenkins, J.M., Schwab, R.A., Lynch, M.T., Knoop, K. and Trott, A. (1994) A Comparative Study of the Percutaneous versus Intraoral Technique for Mental Nerve Block. Academic Emergency Medicine, 1, 509-513. https://doi.org/10.1111/j.1553-2712.1994.tb02542.x

[10] Yeşilyurt, H., Aydinlioglu, A., Kavakli, A., Ekinci, N., Eroglu, C., Hacialiogullari, M. and Diyarbakirli, S. (2008) Local Differences in the Position of the Mental Foramen. Folia Morphologica, 67, 32-35.

[11] Whitworth, J.M., Kanaa, M.D., Corbett, I.P. and Meechan, J.G. (2007) Influence of 
Injection Speed on the Effectiveness of Incisive/Mental Nerve Block: A Randomized, Controlled, Double-Blind Study in Adult Volunteers. Journal of Endodontics, 33, 1149-1154. https://doi.org/10.1016/j.joen.2007.07.016

[12] Jaber, A., Whitworth, J.M., Corbett, I.P., Al-Baqshi, B., Jauhar, S. and Meechan, J.G. (2013) Effect of Massage on the Efficacy of the Mental and Incisive Nerve Block. Anesthesia Progress, 60, 15-20. https://doi.org/10.2344/12-00024.1

Submit or recommend next manuscript to SCIRP and we will provide best service for you:

Accepting pre-submission inquiries through Email, Facebook, LinkedIn, Twitter, etc. A wide selection of journals (inclusive of 9 subjects, more than 200 journals) Providing 24-hour high-quality service User-friendly online submission system Fair and swift peer-review system Efficient typesetting and proofreading procedure Display of the result of downloads and visits, as well as the number of cited articles Maximum dissemination of your research work

Submit your manuscript at: http://papersubmission.scirp.org/ Or contact ss@scirp.org 